\section{RMD Open}

Rheumatic \&

Musculoskeletal Diseases

\title{
Prevalence of axial spondyloarthritis in patients with acute anterior uveitis: a cross-sectional study utilising MRI
}

To cite: Sykes MP, Hamilton L, Jones C, et al. Prevalence of axial spondyloarthritis in patients with acute anterior uveitis: a cross-sectional study utilising MRI. RMD Open 2018:4:e000553. doi:10.1136/ rmdopen-2017-000553

- Prepublication history for this paper is available online. To view these files, please visit the journal online (http://dx.doi. org/10.1136/rmdopen-2017000553).

Received 3 October 2017 Revised 14 January 2018 Accepted 30 January 2018
Check for updates

${ }^{1}$ Department of Rheumatology, Norfolk and Norwich University Hospitals NHS Foundation Trust, Norwich, UK

${ }^{2}$ Department of Ophthalmology, Norfolk and Norwich University Hospitals NHS Foundation Trust, Norwich, UK

Correspondence to

Dr Mark P Sykes;

drmarksykes@hotmail.co.uk

\section{ABSTRACT}

Objective Acute anterior uveitis (AAU) is the most common extra-articular manifestation of axial spondyloarthritis $(\operatorname{axSpA})$. In this study, patients presenting with AAU were evaluated clinically and with MRI in order to estimate the prevalence of axSpA.

Methods Consecutive patients presenting to a university teaching hospital between February 2014 and March 2015 with AAU were invited to participate. Those with a history of chronic back pain (CBP) beginning $<45$ years were evaluated clinically and with MRI of thoracolumbar spine and sacroiliac joints.

Results 0 f 366 patients with AAU, 57 had a pre-existing diagnosis of axSpA; 77 others fulfilled the study eligibility criteria and $73(95 \%)$ completed the study. Seventeen patients $(23.3 \%)$ were diagnosed with axSpA by an experienced rheumatologist; of these, eight were human leucocyte antigen-B27 negative. Including those with a previous diagnosis, this equates to a minimum axSpA prevalence of $20.2 \%$; one-quarter of patients were previously undiagnosed.

Conclusion This is the first study to actively search for the presence of axSpA in unselected patients presenting with AAU utilising MRI as an essential part of the assessment. There is a significant burden of undiagnosed axSpA in patients with AAU, but there does not appear to be a simple mechanism for screening. We recommend that ophthalmologists refer all patients with AAU with CBP, onset $<45$ years, to rheumatology for further evaluation.

\section{INTRODUCTION}

Axial spondyloarthritis (axSpA) is a chronic inflammatory disease which primarily affects the axial skeleton. The prevalence is approximately $0.7 \%$ in the general population, ${ }^{1}$ and there is a strong genetic association with human leucocyte antigen (HLA)-B27. ${ }^{2}$ Symptoms usually begin in the second or third decade $^{3}$ and can have a major impact on health and quality of life. ${ }^{4}$ The spectrum of axSpA as defined by the Assessment of Spondyloarthritis International Society (ASAS) includes non-radiographic axSpA and ankylosing spondylitis (AS). ${ }^{2}$

Acute anterior uveitis (AAU) is the most common extra-articular manifestation of

\section{Key messages}

What is already known about this subject?

- Acute anterior uveitis (AAU) is known to be the most common extra-articular manifestation of axial spondyloarthritis (axSpA).

What does this study add?

- In this study, the minimum prevalence of axSpA in AAU was $20.2 \%$, with nearly one-quarter of patients previously undiagnosed despite many years of back pain.

How might this impact on clinical practice?

- There is no easy referral strategy; previously published pathways would have missed a significant amount of new diagnoses in our cohort.

- We recommend that ophthalmologists refer all patients with AAU with chronic back pain, onset $<45$ years, to rheumatology for further evaluation regardless of human leucocyte antigen-B27 status, gender or number of episodes of AAU.

$\operatorname{axSpA}{ }^{5}{ }^{6} ;$ its prevalence increasing with disease duration. ${ }^{7}$ Diagnostic delay is reported frequently in $\operatorname{axSpA}^{389}$ and is associated with worse outcomes. ${ }^{10}$ Given that spinal symptoms usually precede the first episode of AAU, targeted screening of patients presenting with AAU may enable an earlier diagnosis of axSpA.

In this study, patients with AAU were evaluated clinically by an experienced rheumatologist and underwent MRI in order to estimate the prevalence of axSpA and determine the hidden burden of disease.

\section{METHODS}

\section{Patients}

Consecutive adult patients presenting to the ophthalmology department of a teaching hospital with a verified diagnosis of non-traumatic, non-infective AAU between February 2014 and March 2015 were invited by letter to participate. A further letter was sent to 
non-responders. Patients with a self-reported history of chronic back pain (CBP) beginning before the age of 45 years were included. Those with a pre-existing diagnosis of axSpA, sarcoidosis or Behçet's disease, or in whom MRI was contraindicated, were not investigated further. The hospital notes of patients with a reported diagnosis of axSpA, including AS, were interrogated to confirm that the diagnosis had already been made by an experienced rheumatologist.

\section{Clinical assessment}

Patients who agreed to participate were reviewed by an experienced rheumatologist; clinical assessment included history, physical examination, patient-reported outcome measures and laboratory investigations.

\section{MRI}

MR examinations were performed using a standard protocol for imaging individuals with suspected axSpA, including spectral fat saturation images of the thoracolumbar spine and sacroiliac joints (SIJ). Images were reported by experienced musculoskeletal radiologists blinded to the clinical data and verified by an experienced rheumatologist (MS).

\section{Diagnosis}

The diagnosis of axSpA was made by an experienced rheumatologist following review of the clinical history, examination, laboratory and MRI findings.

\section{Statistics}

Results are reported as means (compared using the two-tailed Student's t-test) or percentages (compared using the $\mathrm{X}^{2}$ test or Fisher's exact probability test).

\section{RESULTS}

Recruitment through the study is shown in figure 1. Of 366 patients who presented with non-traumatic, non-infective AAU, 241 (66\%) responded to the invitation; 57 subjects were already diagnosed with axSpA (verified from clinical notes); 77 others were eligible for the study and $73(95 \%)$ completed the study, including undergoing MRI. Responders were older than non-responders $(\mathrm{P}<0.0001)$ and were more likely to be female $(\mathrm{P}=0.006)$.

Seventeen subjects $(23.3 \%)$ were diagnosed with axSpA by an experienced rheumatologist. Of these, 13 fulfilled the ASAS classification criteria ${ }^{2}$ (12 imaging and one clinical). Of the four remaining patients, three had widespread entheseal oedema on spinal MRI, consistent with the ASAS definition of a positive spinal MRI ${ }^{11}$ and although the fourth patient had an equivocal SIJ MRI, the clinical phenotype was typical of axSpA in view of prominent inflammatory-type back pain (IBP) and Crohn's disease which was already being treated with infliximab. Twelve additional patients fulfilled the clinical arm of the ASAS classification criteria but were not considered to have axSpA when assessed by an experienced rheumatologist.

Table 1 summarises the MRI findings in the patients newly diagnosed with axSpA.

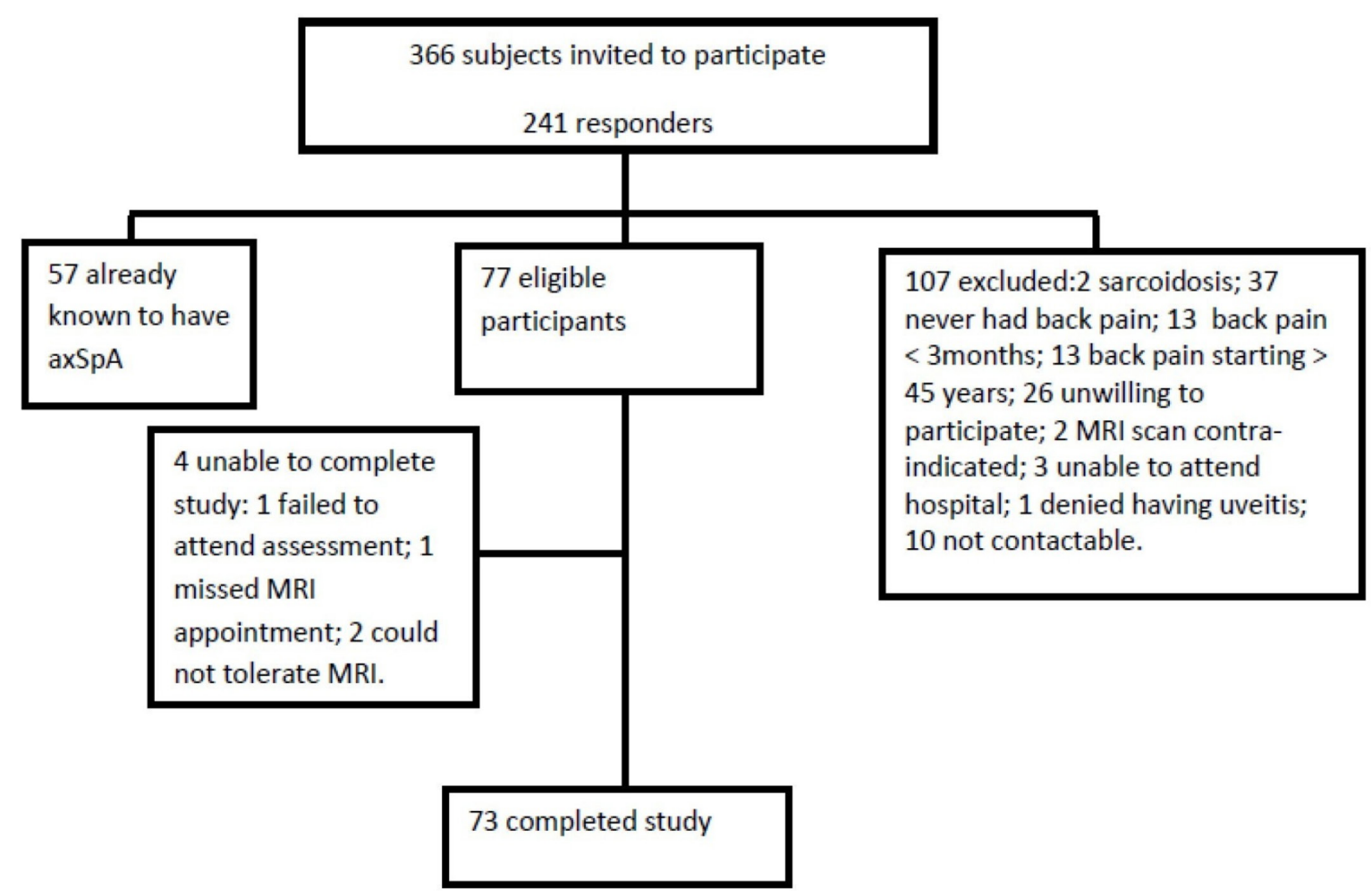

Figure 1 Consort diagram. AxSpA, axial spondyloarthritis. 
Table $1 \mathrm{MRI}$ findings in patients diagnosed with axial spondyloarthritis

\begin{tabular}{|c|c|c|c|}
\hline Patient number & Active changes & Chronic changes & $\begin{array}{l}\text { Meets ASAS definition of } \\
\text { positive SIJ MRI ? }\end{array}$ \\
\hline $\begin{array}{l}1 \\
43, \text { male } \\
\text { B27 positive }\end{array}$ & Single area of SIJ BMO & Fatty changes around SIJs & Yes \\
\hline $\begin{array}{l}2 \\
58, \text { male } \\
\text { B27 negative }\end{array}$ & $\begin{array}{l}\text { Multiple inflammatory vertebral } \\
\text { corner lesions, but no SIJ BMO }\end{array}$ & No & No \\
\hline $\begin{array}{l}4 \\
40, \text { female } \\
\text { B27 negative }\end{array}$ & Bilateral SIJ BMO & SIJ erosions & Yes \\
\hline $\begin{array}{l}6 \\
69, \text { male } \\
\text { B27 negative }\end{array}$ & $\begin{array}{l}\text { Right SIJ BMO and BMO of } \\
\text { multiple thoracic costovertebral } \\
\text { joints }\end{array}$ & $\begin{array}{l}\text { Fused left SIJ, sclerosis } \\
\text { of multiple thoracic } \\
\text { costovertebral joints }\end{array}$ & Yes \\
\hline $\begin{array}{l}7 \\
31, \text { female } \\
\text { B27 negative }\end{array}$ & $\begin{array}{l}\text { Single non-specific area of BMO } \\
\text { around left SIJ }\end{array}$ & None & No \\
\hline $\begin{array}{l}8 \\
34, \text { female } \\
\text { B27 negative }\end{array}$ & Left SIJ BMO & $\begin{array}{l}\text { Erosion of right SIJ, multiple } \\
\text { vertebral fatty corner lesions in } \\
\text { thoracic spine }\end{array}$ & Yes \\
\hline $\begin{array}{l}9 \\
58, \text { male } \\
\text { B27 positive }\end{array}$ & Left SIJ BMO & $\begin{array}{l}\text { Ankylosis right SIJ, erosions } \\
\text { left SIJ }\end{array}$ & Yes \\
\hline $\begin{array}{l}12 \\
31, \text { male } \\
\text { B27 negative }\end{array}$ & Bilateral SIJ BMO & None & Yes \\
\hline $\begin{array}{l}13 \\
42, \text { male } \\
\text { B27 positive }\end{array}$ & Left SIJ BMO & $\begin{array}{l}\text { Vertebral fatty corner lesions } \\
\text { T7-T12 }\end{array}$ & Yes \\
\hline $\begin{array}{l}14 \\
49, \text { female } \\
\text { B27 positive }\end{array}$ & $\begin{array}{l}\text { Bilateral SIJ BMO and two } \\
\text { inflammatory vertebral corner } \\
\text { lesions in thoracolumbar spine }\end{array}$ & Fatty change both SIJs & Yes \\
\hline $\begin{array}{l}15 \\
58, \text { female } \\
\text { B27 positive }\end{array}$ & Bilateral SIJ BMO & Bilateral SIJ erosions & Yes \\
\hline $\begin{array}{l}16 \\
39, \text { female } \\
\text { B27 positive }\end{array}$ & Bilateral SIJ BMO & $\begin{array}{l}\text { Partial fusion both SIJ } \\
\text { inferiorly }\end{array}$ & Yes \\
\hline $\begin{array}{l}17 \\
45, \text { female } \\
\text { B27 positive }\end{array}$ & $\begin{array}{l}\text { Multiple inflammatory vertebral } \\
\text { corner lesions }\end{array}$ & Sclerotic right SIJ & No \\
\hline
\end{tabular}

ASAS, Assessment of Spondyloarthritis International Society; BMO, bone marrow oedema; SIJ, sacroiliac joint 
Table 2 Clinical characteristics of subjects

\begin{tabular}{|c|c|c|c|}
\hline & AxSpA (physician diagnosis) & Not axSpA & $\begin{array}{l}\text { Test of significance } \\
P \text { value }\end{array}$ \\
\hline Number of subjects & $17(23.3 \%)$ & $56(76.7 \%)$ & N/A \\
\hline Mean age in years (SD) & $48.9(12.0)$ & $47.6(11.8)$ & 0.699 \\
\hline Female & $9(52.9 \%)$ & $37(66.1 \%)$ & 0.394 \\
\hline Human leucocyte antigen-B27 positive & 9 (52.9\%) & $19(25.0 \%)$ & 0.167 \\
\hline $\begin{array}{l}\text { Smoking status } \\
\text { current/ex/never (\%) }\end{array}$ & $35.3 / 17.6 / 47.1$ & $12.7 / 40.0 / 45.5$ & 0.093 \\
\hline $\begin{array}{l}\text { Mean number of episodes of uveitis - patient } \\
\text { reported (SD) }\end{array}$ & $7.4(13.9)$ & $3.9(5.2)$ & 0.124 \\
\hline Psoriasis & $1(5.9 \%)$ & $6(10.7 \%)$ & 1.000 \\
\hline Inflammatory bowel disease & $4(23.5 \%)$ & $1(1.8 \%)$ & $0.009^{*}$ \\
\hline Reported history of peripheral joint swelling & $3(17.6 \%)$ & $10(17.9 \%)$ & 1.000 \\
\hline Family history of axSpA & $1(5.9 \%)$ & $3(5.4 \%)$ & 1.000 \\
\hline Mean duration of back pain in years (SD) & $23.6(13.2)$ & $17.8(10.3)$ & 0.061 \\
\hline $\begin{array}{l}\text { Mean duration of back pain at first episode of uveitis } \\
\text { in years (SD) }\end{array}$ & $16.2(12.5)$ & $14.5(10.7)$ & 0.511 \\
\hline $\begin{array}{l}\text { Maastricht Ankylosing Spondylitis Enthesitis Score } \\
\text { (SD) }\end{array}$ & $0.47(0.87)$ & $0.59(1.37)$ & 0.738 \\
\hline Joint count (SD) & $0.88(2.55)$ & $0.98(4.84)$ & 0.935 \\
\hline Bath Ankylosing Spondylitis Metrology Index (SD) & $1.64(1.32)$ & $0.69(0.95)$ & $0.001^{*}$ \\
\hline Bath Ankylosing Spondylitis Functional Index (SD) & $2.88(2.21)$ & $2.52(2.27)$ & 0.564 \\
\hline Bath Ankylosing Spondylitis Global Score (SD) & $4.66(1.41)$ & $4.52(2.01)$ & 0.782 \\
\hline $\begin{array}{l}\text { Bath Ankylosing Spondylitis Disease Activity Index } \\
\text { (SD) }\end{array}$ & $3.36(1.66)$ & $3.42(1.92)$ & 0.904 \\
\hline Spinal pain Visual Analogue Score (SD) & $4.47(2.07)$ & $4.42(2.42)$ & 0.936 \\
\hline $\begin{array}{l}\text { Elevated } \\
\text { C-reactive protein }\end{array}$ & $5(29.4 \%)$ & $3(5.4 \%)$ & $0.014^{*}$ \\
\hline $\begin{array}{l}\text { Meets Assessment of Spondyloarthritis International } \\
\text { Society inflammatory back pain criteria }\end{array}$ & $6(35.3 \%)$ & $23(41.1 \%)$ & 0.781 \\
\hline
\end{tabular}

Test of significance is two-tailed t-test for continuous variables and $\chi^{2}$ test or Fisher's exact probability test for categorical variables. Unless otherwise indicated values are $\mathrm{n}(\%)$.

*Statistical significance.

AxSpA, axial spondyloarthritis; N/A, not applicable.

Findings in the 56 patients not diagnosed with axSpA were: degenerative/mechanical spinal changes (including prolapsed intervertebral discs, dehydrated intervertebral discs, lumbar spondylosis, spondylolisthesis, scoliosis and facet joint osteoarthritis) in 40 patients; of these, five had a single 'inflammatory' corner lesion at one level, associated with mechanical disc disease; two had Scheuermann's disease; six had osteoarthritis of the SIJs with a small area of secondary bone marrow oedema (BMO) in two of these patients; osteitis condensans ilii in one patient and fibrous dysplasia in the iliac bone in one patient. Some patients had more than one of these findings and there were 10 entirely normal scans.

Including those with a previous diagnosis verified by an experienced rheumatologist (57 patients), this equates to an estimated minimum axSpA prevalence of $20.2 \%$ (95\% CI 16.1 to 24.3 ). Of these, $22.9 \%$ were previously undiagnosed.
Table 2 outlines the demographics and clinical characteristics of study participants.

Those diagnosed with axSpA were more likely to be have a raised C-reactive protein $(\mathrm{P}=0.014)$, have a prior diagnosis of inflammatory bowel disease $(\mathrm{P}=0.009)$ and have a higher Bath Ankylosing Spondylitis Metrology Index $(\mathrm{P}=0.001)$. A larger proportion of patients diagnosed with axSpA were HLA-B27 positive, but this did not reach statistical significance. IBP did not predict a physician diagnosis of axSpA.

Five patients $(29.4 \%)$ were diagnosed following a single episode of uveitis. Two of these patients were HLA-B27 negative.

\section{DISCUSSION}

This is the first study to actively search for the presence of axSpA in unselected patients presenting with AAU 
utilising MRI as an essential part of the assessment. Including patients with a prior diagnosis, the minimum prevalence of axSpA is $20.2 \%$, with nearly one-quarter of patients previously undiagnosed despite years of back pain. This represents a significant hidden burden of disease.

Two other studies have recently investigated axSpA prevalence in patients with AAU. ${ }^{12}{ }^{13}$ However, as known cases were excluded, neither study could report the overall prevalence of axSpA in the group. Juanola $e t \mathrm{al}^{12}$ also excluded HLA-B27 negative patients with a single episode of AAU, but in our cohort, $12 \%$ of patients newly diagnosed with axSpA met those exclusion criteria. Haroon $e t a l^{13}$ reported that $40 \%$ of patients presenting with AAU had undiagnosed SpA, although it is unclear how many of these patients underwent MRI.

Although this is a relatively small single-centre study, the sample size was sufficient to calculate the prevalence with a reasonable degree of precision. The main risk of bias is in the self-selection of responders to the initial invitation; responders were significantly more likely to be older and female. We have made the assumption that non-responders did not have back pain, or by extension axSpA, and have presented our results as minimum estimated prevalence. However, we accept this could have led to an underestimate of the overall prevalence. We also based our calculations on diagnoses made by an experienced rheumatologist; it is not always clear how other studies arrived at their figures and, for example, had we included all patients who met the ASAS classification criteria within the 'positive diagnoses' (which we are very clear is not how classification criteria should be used), $40 \%$ patients assessed would have been assigned a 'diagnosis' of axSpA.

Establishing a diagnosis of axSpA is difficult; consequently, there is often a considerable delay to diagnosis and a potential to 'over diagnose' based on subtle or non-specific MRI changes. ${ }^{14}$ The gold standard is 'physician-verified diagnosis', which is based on clinical assessment including interpretation of laboratory tests and imaging. Classification criteria should only be applied following diagnosis and have been developed to ensure homogeneity in groups of patients for research purposes ${ }^{15}$ although the positive predictive validity of the ASAS axSpA classification criteria to forecast an expert's diagnosis of 'SpA' after more than 4 years is good. ${ }^{16}$ The imaging arm of the ASAS axSpA classification criteria requires the presence of sacroiliitis on MRI or X-ray and the ASAS/Outcome Measures in Rheumatology definition of a positive spinal MRI ${ }^{11}$ is not currently included in the formal ASAS classification system and so potentially patients with spinal inflammation in the absence of sacroiliac inflammation could be overlooked. This observation has been well described especially in patients with longstanding disease. ${ }^{17}$ One of the potential limitations of an MRI-based study is the potential to over or misinterpret MRI findings. Three of our B27-negative patients diagnosed as axSpA did not fulfil the ASAS definition of a positive SIJ MRI; however, we consider any potential 'over diagnosis' unlikely by virtue of them having a typical axSpA clinical phenotype verified an experienced rheumatologist including IBP onset $<45$ years, recurrent AAU and extensive spinal inflammatory lesions seen on MRI. Conversely, there were many more patients (12) who fulfilled the ASAS classification criteria who we considered not to have the disease.

Other potential limitations include the fact that only a single MRI was undertaken, so potentially fluctuating BMO could have been missed ${ }^{18} 19$ and that plain radiographs were not undertaken. This was due to the fact that ethics approval was not forthcoming as it was considered that this would expose too many patients to unnecessary radiation, and MRI was being undertaken as a more comprehensive imaging modality. As a result of a lack of plain radiographs, we cannot state how many patients met the modified New York Criteria for AS. Many patients had chronic changes on MRI which may reflect the long average delay to diagnosis of over 20 years. Had these patients been screened for axSpA following their first episode of AAU, the diagnostic delay could have been reduced by 7 years on average. Given the high prevalence of axSpA among patients with AAU, targeted screening may offer a unique opportunity to identify undiagnosed axSpA especially as AAU may prompt the first interaction with secondary care. ${ }^{20}$

In clinical practice, HLA-B27 positivity is often the trigger for a rheumatology referral in patients with AAU. Indeed, the Dublin Uveitis Evaluation Tool (DUET) algorithm proposed by Haroon et al prompts referral if a patient is HLA-B27 positive (or has co-existing psoriasis or peripheral arthritis), with high reported sensitivity and specificity of $96 \%$ and $97 \%$, respectively. ${ }^{13}$ This may reflect the status of HLA-B27 as the anchor criterion for the clinical arm of the ASAS criteria. In our cohort, the sensitivity and specificity of the DUET algorithm were $52.9 \%$ (95\% CI 27.8 to 77.0 ) and $67.9 \%$ (95\% CI 54.0 to 79.7 ), respectively. Nearly half of new diagnoses were HLA-B27 negative (none of whom had psoriasis or a recent history of joint pains requiring a GP visit). By applying the DUET algorithm, these HLA-B27 negative patients would have been overlooked. Similarly, the presence of IBP did not predict the diagnosis of axSpA or a positive MRI. Had we relied on IBP rather than CBP before age 45 as a referral strategy, nearly two-thirds of new diagnoses would have been overlooked.

In summary, there is a high prevalence of undiagnosed axSpA in patients presenting to secondary care with AAU. There does not appear to be a simple mechanism for screening these patients, so given the significant burden of 'hidden' axSpA, we recommend that ophthalmologists refer all patients with AAU with CBP, onset $<45$ years, to rheumatology for further evaluation regardless of HLA-B27 status, gender or number of episodes of AAU. Close collaboration between rheumatology and ophthalmology is necessary in order to facilitate this targeted approach to patient care. 
Contributors All authors were involved in the data collection and had input into the final report.

Funding This study was funded by AbbVie Ltd.

Competing interests None declared.

Patient consent Obtained.

Ethics approval Ethical approval was provided by NRES Committee East of England - Norfolk (reference number 13/EE/0442).

Provenance and peer review Not commissioned; externally peer reviewed.

Data sharing statement Additional data may be available by contacting the corresponding author.

Open Access This is an Open Access article distributed in accordance with the Creative Commons Attribution Non Commercial (CC BY-NC 4.0) license, which permits others to distribute, remix, adapt, build upon this work non-commercially, and license their derivative works on different terms, provided the original work is properly cited and the use is non-commercial. See: http://creativecommons.org/ licenses/by-nc/4.0/

(c) Article author(s) (or their employer(s) unless otherwise stated in the text of the article) 2018. All rights reserved. No commercial use is permitted unless otherwise expressly granted.

\section{REFERENCES}

1. Strand V, Rao SA, Shillington AC, et al. Prevalence of axial spondyloarthritis in United States rheumatology practices: assessment of spondyloarthritis international society criteria versus rheumatology expert clinical diagnosis. Arthritis Care Res 2013;65:1299-306.

2. Rudwaleit $M$, van der Heijde $D$, Landewé $R$, et al. The development of assessment of SpondyloArthritis international Society classification criteria for axial spondyloarthritis (part II): validation and final selection. Ann Rheum Dis 2009;68:777-83.

3. Feldtkeller E, Khan MA, van der Heijde D, et al. Age at disease onset and diagnosis delay in HLA-B27 negative vs. positive patients with ankylosing spondylitis. Rheumatol Int 2003;23:61-6.

4. Ward MM. Health-related quality of life in ankylosing spondylitis: a survey of 175 patients. Arthritis Care Res 1999;12:247-55.

5. Essers I, Ramiro S, Stolwijk C, et al. Characteristics associated with the presence and development of extra-articular manifestations in ankylosing spondylitis: 12-year results from OASIS. Rheumatology 2015;54:633-40.

6. Stolwijk C, van Tubergen A, Castillo-Ortiz JD, et al. Prevalence of extra-articular manifestations in patients with ankylosing spondylitis: a systematic review and meta-analysis. Ann Rheum Dis 2015;74:65-73.
7. Stolwijk C, Essers I, van Tubergen A, et al. The epidemiology of extra-articular manifestations in ankylosing spondylitis: a populationbased matched cohort study. Ann Rheum Dis 2015;74:1373-8.

8. Hamilton L, Gilbert A, Skerrett J, et al. Services for people with ankylosing spondylitis in the UK--a survey of rheumatologists and patients. Rheumatology 2011;50:1991-8.

9. Sykes MP, Doll H, Sengupta R, et al. Delay to diagnosis in axial spondyloarthritis: are we improving in the UK? Rheumatology 2015;54:kev288-4.

10. Seo MR, Baek HL, Yoon $\mathrm{HH}$, et al. Delayed diagnosis is linked to worse outcomes and unfavourable treatment responses in patients with axial spondyloarthritis. Clin Rheumatol 2015;34:1397-405.

11. Hermann KG, Baraliakos X, van der Heijde DM, et al. Descriptions of spinal MRI lesions and definition of a positive MRI of the spine in axial spondyloarthritis: a consensual approach by the ASAS/ OMERACT MRI study group. Ann Rheum Dis 2012;71:1278-88.

12. Juanola $X$, Loza Santamaría E, Cordero-Coma M, et al. Description and prevalence of spondyloarthritis in patients with anterior uveitis: The SENTINEL interdisciplinary collaborative project. Ophthalmology 2016;123:1632-6.

13. Haroon M, O'Rourke M, Ramasamy $\mathrm{P}$, et al. A novel evidence-based detection of undiagnosed spondyloarthritis in patients presenting with acute anterior uveitis: the DUET (Dublin Uveitis Evaluation Tool). Ann Rheum Dis 2015;74:1990-5.

14. Deodhar A. Editorial: Sacroiliac joint magnetic resonance imaging in the diagnosis of axial spondyloarthritis: "A tiny bit of white on two consecutive slices" may be objective, but not specific. Arthritis Rheumatol 2016;68:775-8.

15. Deodhar A, Strand V, Kay J, et al. The term 'non-radiographic axial spondyloarthritis' is much more important to classify than to diagnose patients with axial spondyloarthritis. Ann Rheum Dis 2016;75:791-4

16. Sepriano A, Landewé $R$, van der Heijde D, et al. Predictive validity of the ASAS classification criteria for axial and peripheral spondyloarthritis after follow-up in the ASAS cohort: a final analysis. Ann Rheum Dis 2016;75:1034-42.

17. van der Heijde D, Sieper J, Maksymowych WP, et al. Spinal inflammation in the absence of sacroiliac joint inflammation on magnetic resonance imaging in patients with active nonradiographic axial spondyloarthritis. Arthritis Rheumatol 2014;66:667-73.

18. van Onna M, van Tubergen A, Jurik AG, et al. Natural course of bone marrow oedema on magnetic resonance imaging of the sacroiliac joints in patients with early inflammatory back pain: a 2-year followup study. Scand J Rheumatol 2015;44:129-34.

19. Baraliakos X, Sieper J, Chen S, et al. Non-radiographic axial spondyloarthritis patients without initial evidence of inflammation may develop objective inflammation over time. Rheumatology 2017;56:1162-6.

20. Fernández-Melón J, Muñoz-Fernández S, Hidalgo V, et al Uveitis as the initial clinical manifestation in patients with spondyloarthropathies. J Rheumatol 2004;31:524-7. 